\title{
Perfil proteico e metabolismo oxidativo de cordeiros experimentalmente infectados pelo Haemonchus contortus e suplementados com selênio e vitamina E
}

\author{
Protein profile and oxidative metabolism of lambs experimentally infected with Haemonchus \\ contortus and supplemented with selenium and vitamin $\mathbf{E}$
}

\author{
Paula Rocha Sampaio Junchem Nicolodi' ${ }^{\mathrm{I}}$ Emmanuel Veiga de Camargo ${ }^{\mathrm{II}}$ Diego Zeni ${ }^{\mathrm{II}}$ \\ Ricardo Xavier da Rocha ${ }^{\text {II }}$ Fernanda Cavallini Cyrillo ${ }^{\text {III }}$ Fernando Nogueira de Souza ${ }^{\text {III }}$ \\ Alice Maria Melville Della Libera' ${ }^{\mathrm{III}}$ Carlos Bondan $^{\mathrm{IV}}$ Marta Lizandra do Rêgo Leal ${ }^{\mathrm{V}}$
}

\section{RESUMO}

Para avaliar a influência da suplementação com selênio e vitamina $E$ sobre o perfil proteico e metabolismo oxidativo de cordeiros infectados experimentalmente pelo Haemonchus contortus, trinta cordeiros fêmeas foram distribuídos em quatro grupos: $G 1$ ( $n=10)$ : animais infectados; G2 ( $n=10)$ : infectados e suplementados; $G 3(n=5)$ : controle; e G4 (n=5): não infectados e suplementados. Os grupos 1 e 2 receberam 500 larvas de $\boldsymbol{H}$. contortus (L3), via oral, por um período de 20 dias, com intervalo de dois dias entre as doses. A suplementação nos grupos 2 e 4 foi realizada no dia zero, com $0,1 \mathrm{mg} \mathrm{kg}^{-1}$ de Selenito de sódio $(1,67 \%)$ e com $2.000 U \mathrm{UI}$ de vitamina $E$ por via intramuscular (IM). Somente a vitamina E foi reaplicada no dia 30 . As coletas de sangue para determinação do perfil proteico (proteína total, albumina, alfa, beta e gamaglobulina) e metabolismo oxidativo (espécies reativas ao ácido tiobarbitúrico-TBARS e a enzima glutationa peroxidase (GSPX) foram realizadas nos dias zero, 20, 30, 45, 60 e 80. OPG foi quantificado nos dias 0, 20 ,45 e 80. Em relação aos valores de proteínas totais, albumina, betaglobulina e gamaglobulina, as principais diferenças foram observadas quando os grupos parasitados foram comparados com o grupo somente suplementado; e este manteve valores mais elevados. Conclui-se que não há influência da suplementação com selênio e vitamina $E$ no perfil proteico e metabolismo oxidativo quando os cordeiros se encontram severamente parasitados por H.contortus.

Palavras-chave: ovinos, Haemonchus contortus, perfil proteico, metabolismo oxidativo.

\section{ABSTRACT}

The objective of the present study was to describe the influence of supplementation with selenium and vitamin $E$ on the protein and oxidative profiles of lambs experimentally infected with Haemonchus contortus. Thirty female lambs were divided into four groups as follows: $G 1(n=10)$ : infected animals; $G 2(n=10)$ : infected and supplemented; $G 3(n=5)$ : control; $G 4(n=5)$ : non-infected and supplemented. Groups 1 and 2 received $500 \mathrm{H}$. contortus larvae (L3) orally for a period of 20 days, with 2-day intervals between doses. Supplementation in groups 2 and 4 was performed on day zero by injecting $0.1 \mathrm{mg} \mathrm{kg}^{-1}$ of sodium selenite solution (1.67\%) and 2,000IU vitamin E through the intramuscular (IM) route. Vitamin E alone was injected once again on day thirty. The blood samples to determine the protein profile (total protein, albumin, alpha, beta and gamma) and oxidative metabolism (species reactive to thiobarbituric acid and glutathione peroxidase (GSPX) were performed on days zero, 20, 30, 45, 60 and 80. The OPG was quantified on days 0,20, 45 and 80. Regarding the values of total proteins, albumin, beta and gamma globulins, the main differences were observed when the parasitized groups were compared to the supplemented, non-infected group, the latter exhibiting higher values. It is concluded that there is no influence of supplementation with vitamin $E$ and selenium in the protein profile and oxidative metabolism when the lambs are severely parasitized with $\boldsymbol{H}$. contortus.

Key words: sheep, Haemonchus contortus, protein profile, metabolism oxidative.

\footnotetext{
IPrograma de Pós-graduação em Medicina Veterinária (PPGMV), Universidade Federal de Santa Maria (UFSM), Santa Maria, RS, Brasil. IIPPGMV, UFSM, Santa Maria, RS, Brasil.

IIIDepartamento de Clínica Médica, Faculdade de Medicina Veterinária e Zootecnia (FMVZ), Universidade de São Paulo (USP), São Paulo, Brasil.

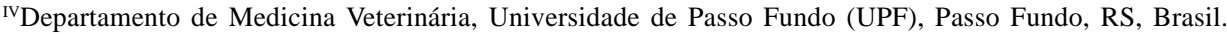

v Departamento de Clínica de Grandes Animais (DCGA), UFSM, Fx. de Camobi, km 9, Campus Universitário, Prédio 97, 97105900, Santa Maria, RS, Brasil. E-mail: marta.leal@pq.cnpq.br. *Autor para correspondência.
} 


\section{INTRODUÇÃO}

Os parasitas gastrintestinais são um grande obstáculo à ovinocultura (ROWE et al., 2008). O principal parasita gastrintestinal dos ovinos é o Haemonchus contortus (H. contortus), que acarreta sérios prejuízos econômicos na ovinocultura mundial (BAKER, 1996).

Grande parte da patogenicidade desse parasita é proveniente de sua hematofagia. Ovinos com intensa parasitose, principalmente jovens, podem apresentar diminuição dos valores hematológicos e perdas proteicas, caracterizadas por hipoproteinemia com hipogamaglobulinemia (ADAMS, 1993).

Entre vários agentes químicos produzidos pelo hospedeiro contra os parasitas, citam-se a produção de radicais livres (KAZURA \& MESNICK, 1984). Radicais livres são qualquer espécie química que possuem um ou mais elétrons não pareados. Essa configuração eletroquímica muito instável confere a essas estruturas alta reatividade e vida curta (HALLIWELL \& GUTTERIDGE, 2007). Uma vez formados, os radicais livres interagem com outras moléculas por meio de reações de oxiredução com o propósito de estabilizar sua configuração eletrônica. A classificação dos radicais livres se dá pelo grupo funcional presente em sua molécula; porém, os processos aeróbicos que envolvem o oxigênio são os mais comuns e seus produtos são denominados de espécies reativas do oxigênio (EROS) (CHIHUAILAF et al., 2002; VALKO et al., 2007). Uma vez formados, os radicais livres buscam estabilizar-se, cedendo ou captando um elétron de espécies vizinhas (SCHANAIDER, 2000). Estas, por sua vez, tornam-se radicais livres e se estabilizam, tomando ou cedendo elétrons de outras substâncias. Cria-se uma reação em cadeia que termina por alterar a conformação, a estrutura ou as funções de proteínas, fosfolipídios de membrana, ácidos nucleicos e outros componentes celulares (RIEGEL, 2000). Essa deteriorização oxidativa dos lipídios polinsaturados é chamada de lipoperoxidação (NORDBERGER \&ARNER, 2001).

O desequilíbrio entre a produção de EROS e a remoção pelos sistemas de defesa antioxidante é denominado de estresse oxidativo. $O$ estresse oxidativo é uma condição celular ou fisiológica de elevada concentração de EROS que causa danos moleculares às estruturas celulares, com consequente alteração funcional e prejuízo das funções vitais (DRÖGE, 2002; HALLIWELL \& GUTTERIDGE, 2007).

Em sistemas aeróbicos, é essencial o equilíbrio entre agente óxido-redutores (como as EROS) e o sistema de defesa antioxidante. Para proteger-se, a célula possui um sistema detoxificador do agente antes que cause lesão, constituído pela glutationa reduzida (GSH), pelo superóxido-dismutase (SOD), pela catalase, pela glutationa-peroxidase (GSH-Px) e pela vitamina E ou pelo reparador onde há a ação do ácido ascórbico, da glutationa-redutase (GSH-Rd) e da glutationa peroxidase (GSHPx), entre outros. Com exceção da vitamina E (a-tocoferol), que é um antioxidante estrutural da membrana, a maior parte dos agentes antioxidantes está no meio intracelular (ALONSO et al., 1997; HALLIWELL \& GUTTERIDGE, 2007).

A presença de selênio (SE) na estrutura da GSH-Px permite que exista uma alta relação entre a concentração sanguínea e tissular de Se com a atividade dessa enzima. A deficiência de Se induz a baixa atividade da GSH-Px, deixando a célula exposta à ação nociva das EROS, o que produz alterações na estrutura de lipídios, proteínas, polissacarídeos, DNA e outras macromoléculas celulares (ARTHUR et al., 2003; HALLIWELL \& GUTTERIDGE, 2007).

A vitamina E é capaz de quelar formas reativas de oxigênio, diminuindo a formação de peróxidos, já que muitas dessas moléculas são autotóxicas e podem destruir neutrófilos e macrófagos. Dessa forma, essa vitamina protege a membrana lipídica, os receptores e outros componentes celulares envolvidos na modulação da resposta imunológica (MEYDANI, 1995; HALLIWELL \& GUTTERRIDGE, 2007).

O objetivo deste estudo foi avaliar o efeito da suplementação com selênio e vitamina E sobre o perfil proteico e metabolismo oxidativo de cordeiros parasitados experimentalmente pelo $\boldsymbol{H}$. contortus.

\section{MATERIAL E MÉTODOS}

Foram utilizados 30 cordeiros fêmeas, cruza texel, com idade entre quatro e cinco meses. Os animais foram distribuídos em quatro grupos experimentais. Grupo 1 (n=10): animais infectados com larvas de $\boldsymbol{H}$. contortus; Grupo $2(\mathrm{n}=10)$ : animais infectados com as larvas de $\boldsymbol{H}$. contortus e suplementados com $0,1 \mathrm{mg} \mathrm{kg}^{-1} \mathrm{de}$ Selenito de sódio ${ }^{\mathrm{a}}(1,67 \%)$ (ROOKE et al., 2004) e 2.000UI de vitamina $\mathrm{E}^{\mathrm{b}}$ (acetato DL-á-tocoferol) (LOPES et al., 2003) por via IM; Grupo 3 ( $n=5)$ : controle; e Grupo $4(n=5)$ : animais nao infectados e suplementados com vitamina E e selênio.

Antes do período experimental, os animais permaneceram por 40 dias alocados em baias coletivas (1 baia para cada grupo) localizadas no Hospital Veterinário da Universidade Federal de Santa Maria (HVU), para adaptação ao alimento e ao ambiente experimental. Cada animal recebeu água e sal comum à 
vontade e foi alimentado com $1.0 \mathrm{~kg}$ de feno de azevém (Proteína bruta $(\mathrm{PB})=8 \%$ ) e 150 gramas de ração $(\mathrm{PB}=21 \%$ ) por dia, o que totalizou uma dieta com $9,6 \%$ de PB. Três dias após a chegada dos animais ao HVU, foram realizados o OPG e aplicação única de associação de anti-helminticos: levamisole ${ }^{c}$ e closantel + albendazole $^{\text {d }}$. Durante o período de adaptação, os animais foram monitorados pela OPG, com resultados negativos em todas as avaliações.

Cada animal dos grupos 1 e 2 recebeu 500 larvas (L3) de $\boldsymbol{H}$. contortus por via oral, por um período de 20 dias (ROWE et al., 2008), com intervalo de dois dias entre as doses, iniciando a contaminação no dia zero. As larvas foram obtidas por meio da técnica de coprocultura realizada no laboratório de microbiologia e parasitologia do Centro de Ciência da Saúde da Universidade Federal de Santa Maria (ROBERTS \& O’SULLIVAN, 1950), sendo obtidas apenas larvas de Haemonchus contortus. A suplementação nos grupos 2 e 4 com selênio foi realizada no dia zero, e a vitamina E (G2 e G4) foi aplicada nos dias zero e 30 do experimento.

Foram realizadas coletas de amostras sanguíneas por punção da jugular, pelo sistema vacutainer ${ }^{\circledR}$, com o uso de EDTA como anticoagulante. As amostras de sangue foram obtidas nos dias zero (T0), 20 (T1), 30 (T2), 45 (T3), 60 (T4) e 80 (T5). Após coleta, as amostras foram centrifugadas, sendo o soro desprezado e as hemácias acondicionadas em eppendorfs e armazenadas a $-20^{\circ} \mathrm{C}$, para posterior analise. A peroxidação lipídica foi determinada nos eritrócitos de acordo com o método de formação de espécies reativas ao ácido tiobarbitúrico (TBARS) (o TBARS quantifica, nos eritrócitos, a concentração de malondialdeido, que é o metabolito final da lipoperoxidação) (OHKAWA et al., 1979). A quantificação da GSH-Px nos eritrócitos baseou-se na redução do ditionitrobenzeno. O perfil eletroforético das proteínas (proteína total, albumina, alfa, beta e gamaglobulinas) foi realizado em cuba de eletroforese, sendo utilizadas fitas de acetato de celulose ${ }^{\mathrm{e}}$ (LEAL et al.,2003).

Os dados foram submetidos à análise de variância (ANOVA) e ao teste de Duncan, para comparação entre pares de médias. O nível de significância utilizado foi de 5\%. Para o estudo da relação entre duas variáveis, foram utilizadas as análises de regressão linear e o coeficiente de correlação. A significância obtida na regressão linear foi avaliada por meio do teste F. Foram consideradas diferenças significativas quando o $\mathrm{P}$ foi inferior a 0,05. A relação foi considerada alta quando $r>0,60$; média quando os valores de $r$ estavam entre 0,30 e 0,60 ; e baixa quando $r<0,30$ (SAMPAIO, 1998).

\section{RESULTADOS E DISCUSSÃO}

Os resultados obtidos na avaliação do perfil proteico e do metabolismo oxidativo de cordeiros infectados experimentalmente pelo Haemonchus contortus e suplementados com selênio e vitamina E podem ser visualizados na tabela 1 .

No momento zero, não houve diferença na OPG entre os grupos experimentais (Tabela 1). Os grupos (1 e 2) infectados experimentalmente pelo $\mathrm{H}$ Contortus exibiram maiores valores de OPG em relação aos grupos que não receberam Larvas de $\boldsymbol{H}$. contortus (3 e 4), nos tempos 1,3 e 5 (Tabela 1) $(\mathrm{P}<0,05)$. No entanto, houve uma infecção branda nos grupos 3 e 4 durante o período de estudo, provavelmente em decorrência da proximidade das baias onde os animais foram alocados.

As proteínas totais e a fração albumina exibiram comportamento similar durante o período experimental. Os animais do grupo 4 obtiveram maiores valores desses constituintes bioquímicos no T4 e T5, em comparação com os animais dos grupos 1, 2 e $3(\mathrm{P}<0,008)$. No tempo 2, menores valores de proteína total e albumina foram observados no grupo de animais infectados pelo $\boldsymbol{H}$. contortus e não suplementados, em relação aos demais grupos estudados (Tabela 1).

Dentre os efeitos deletérios gerados pela infecção pelo $\boldsymbol{H}$. contortus em pequenos ruminantes, destacam-se diminuições nas concentrações séricas de proteínas totais, notadamente a albumina (BLACKBURN et al., 1992). Os cordeiros apenas suplementados com selênio e vitamina E (G4), apesar de terem recebido, durante todo o período experimental, uma dieta com baixo teor proteico, exibiram um incremento na produção de proteínas totais e de albumina aos 60 e 80 dias (Tabela 1). De acordo com RAMIREZ-BRIBIESCA et al. (2005), o pico de ação do selênio pode ocorrer em até 60 dias após sua aplicação, sendo, provavelmente, a suplementação desse mineral o responsável pelo melhor desempenho proteico nos cordeiros desse grupo. Quanto à fração betaglobulina, valores mais elevados foram detectados no T3, T4 e T5 do G4, em relação ao grupo 1. No T3 e T5, os animais do grupo 4 exibiram maiores valores dessa fração proteica quando comparados aos animais do G2 (Tabela 1). Os resultados podem estar associados ao fato de o selênio e a vitamina E serem metabolizados pelo fígado e de que o aumento das betaglobulinas ocorra associado ao aumento no metabolismo hepático (ROOKE et al., 2004; GIERUS, 2007; PAULAe SILVA et al., 2008). 
Tabela 1 - Valores médios e desvio padrão do perfil proteico e metabolismo oxidativo de cordeiros infectados com Haemonchus contortus e suplementados com vitamina E e selênio. Grupo 1: animais somente infectado com as larvas do parasita; grupo 2: animais infectados com as larvas e suplementados com Selenito de sódio (1,67\%) e vitamina E; grupo 3: controle; e grupo 4: animais suplementados com Selenito de sódio (1,67\%) e vitamina E.

\begin{tabular}{|c|c|c|c|c|c|c|c|c|}
\hline \multirow{2}{*}{ G } & \multirow{2}{*}{$\mathrm{T}$} & PT & Alb & Beta & Gama & TBARS & GSH-Px & OPG \\
\hline & & $\mathrm{g} / \mathrm{dl}$ & $\mathrm{g} / \mathrm{dl}$ & $\mathrm{g} / \mathrm{dl}$ & $\mathrm{g} / \mathrm{dl}$ & mda/g hb & $\mathrm{mmol} \mathrm{SH} / \mathrm{l}$ & g \\
\hline \multirow{6}{*}{ G1 } & T0 & $6,4 \pm 0,33^{\mathrm{a}}$ & $3,6 \pm 0,27^{a}$ & $1,03 \pm 0,11^{\mathrm{a}}$ & $1,4 \pm 0,1^{\mathrm{a}}$ & $2,7 \pm 0,37^{\mathrm{a}}$ & $8,8 \pm 3,8^{a}$ & $0,0 \pm 00^{b}$ \\
\hline & $\mathrm{T} 1$ & $5,8 \pm 0,46^{\mathrm{a}}$ & $2,9 \pm 0,1^{\mathrm{a}}$ & $1,04 \pm 0,16^{\mathrm{a}}$ & $1,6 \pm 0,15^{\mathrm{a}}$ & $2,9 \pm 0,38^{\mathrm{a}}$ & $9,6 \pm 4,0^{\mathrm{a}}$ & $6186(2.000)$ \\
\hline & $\mathrm{T} 2$ & $5,3 \pm 0,61^{\mathrm{b}}$ & $2,5 \pm 0,3^{b}$ & $1,02 \pm 0,19^{\mathrm{a}}$ & $1,3 \pm 0,29^{a}$ & $2,5 \pm 1,09^{\mathrm{a}}$ & $8,3 \pm 5,3^{a}$ & - \\
\hline & T3 & $5,5 \pm 1,40^{\mathrm{a}}$ & $3,0 \pm 0,2^{\mathrm{a}}$ & $0,99 \pm 0,05^{b}$ & $1,3 \pm 0,24^{\mathrm{a}}$ & $2,6 \pm 0,89^{\mathrm{a}}$ & $8.4 \pm 9,2^{\mathrm{a}}$ & $8.360 \pm 2.601^{\mathrm{a}}$ \\
\hline & $\mathrm{T} 4$ & $5,5 \pm 1,0^{\mathrm{b}}$ & $3,0 \pm 0,4^{\mathrm{b}}$ & $0,96 \pm 0,11^{\mathrm{b}}$ & $1,2 \pm 0,30^{b}$ & $2,3 \pm 0,60^{\mathrm{b}}$ & $7,6 \pm 1,0^{\mathrm{b}}$ & \\
\hline & $\mathrm{T} 5$ & $5,5 \pm 0,4^{c}$ & $2,6 \pm 0,7^{\mathrm{a}}$ & $0,92 \pm 0,03^{\mathrm{C}}$ & $1,2 \pm 0,50^{\mathrm{a}}$ & $2,3 \pm 0,92^{\mathrm{a}}$ & $7,5 \pm 3,2^{\mathrm{a}}$ & $10.522 \pm 3.643^{\mathrm{a}}$ \\
\hline \multirow{6}{*}{ G2 } & T0 & $6,5 \pm 0,33^{\mathrm{a}}$ & $3,7 \pm 0,27^{a}$ & $0,99 \pm 0,14^{\mathrm{a}}$ & $1,4 \pm 0,10^{\mathrm{a}}$ & $2,8 \pm 0,37^{a}$ & $9,0 \pm 3,8^{\mathrm{a}}$ & $0,0 \pm 0,0^{\mathrm{b}}$ \\
\hline & $\mathrm{T} 1$ & $6,1 \pm 0,46^{\mathrm{a}}$ & $2,8 \pm 0,1^{\mathrm{a}}$ & $1,13 \pm 0,16^{\mathrm{a}}$ & $1,6 \pm 0,15^{\mathrm{a}}$ & $3,1 \pm 0,38^{\mathrm{a}}$ & $10,1 \pm 4,0^{\mathrm{a}}$ & $6450 \pm 1.920^{\mathrm{a}}$ \\
\hline & $\mathrm{T} 2$ & $6,6 \pm 0,62^{\mathrm{a}}$ & $3,3 \pm 0,3^{\mathrm{a}}$ & $1,22 \pm 0,19^{a}$ & $1,7 \pm 0,28^{\mathrm{a}}$ & $3,3 \pm 1,09^{a}$ & $10,7 \pm 5,3^{\mathrm{a}}$ & - \\
\hline & $\mathrm{T} 3$ & $5,7 \pm 1,42^{\mathrm{a}}$ & $3,0 \pm 0,2^{\mathrm{a}}$ & $0,95 \pm 0,05^{\natural}$ & $1,4 \pm 0,24^{\mathrm{a}}$ & $2,8 \pm 0,89^{a}$ & $9,0 \pm 9,2^{\mathrm{a}}$ & $9.220 \pm 3.349^{a}$ \\
\hline & $\mathrm{T} 4$ & $5,9 \pm 1,0^{\mathrm{b}}$ & $3,0 \pm 0,4^{\mathrm{b}}$ & $1,06 \pm 0,11^{\mathrm{ab}}$ & $1,3 \pm 0,60^{b}$ & $2,6 \pm 0,60^{\mathrm{b}}$ & $8,4 \pm 1,0^{\mathrm{b}}$ & \\
\hline & $\mathrm{T} 5$ & $5,9 \pm 0,4^{\mathrm{b}}$ & $2,2 \pm 0,7^{\mathrm{a}}$ & $1,06 \pm 0,08^{b}$ & $1,8 \pm 0,50^{\mathrm{a}}$ & $3,4 \pm 0,91^{\mathrm{a}}$ & $11,1 \pm 3,2^{\mathrm{a}}$ & $10.222 \pm 4.952^{\mathrm{a}}$ \\
\hline \multirow{7}{*}{ G 3} & T0 & $6,2 \pm 0,33^{a}$ & $3,3 \pm 0,27^{\mathrm{a}}$ & $1,09 \pm 0,11^{\mathrm{a}}$ & $1,4 \pm 0,10^{\mathrm{a}}$ & $2,7 \pm 0,37^{\mathrm{a}}$ & $8,8 \pm 3,8^{a}$ & $0,0 \pm 0,0^{\mathrm{b}}$ \\
\hline & $\mathrm{T} 1$ & $5,8 \pm 0,46^{a}$ & $2,9 \pm 0,1^{\mathrm{a}}$ & $0,99 \pm 0,16^{\mathrm{a}}$ & $1,5 \pm 0,15^{\mathrm{a}}$ & $2,9 \pm 0,38^{\mathrm{a}}$ & $9,4 \pm 4,0^{\mathrm{a}}$ & $770 \pm 560^{\mathrm{b}}$ \\
\hline & $\mathrm{T} 2$ & $6,2 \pm 0,61^{\mathrm{ab}}$ & $3,2 \pm 0,3^{\mathrm{a}}$ & $1,10 \pm 0,19^{\mathrm{a}}$ & $1,5 \pm 0,29^{\mathrm{a}}$ & $2,8 \pm 1,09^{\mathrm{a}}$ & $9,2 \pm 5,3^{a}$ & - \\
\hline & T3 & $6,5 \pm 1,41^{\mathrm{a}}$ & $3,2 \pm 0,2^{\mathrm{a}}$ & $1,2 \pm 0,05^{\mathrm{a}}$ & $1,6 \pm 0,24^{\mathrm{a}}$ & $3,1 \pm 0,89^{a}$ & $10,0 \pm 9,2^{\mathrm{a}}$ & $667 \pm 517^{b}$ \\
\hline & $\mathrm{T} 4$ & $6,2 \pm 1,0^{\mathrm{b}}$ & $3,2 \pm 0,4^{b}$ & $1,07 \pm 0,11^{\mathrm{ab}}$ & $1,5 \pm 0,70^{\mathrm{ab}}$ & $3,0 \pm 0,60^{\mathrm{ab}}$ & $9,7 \pm 1,0^{\mathrm{ab}}$ & \\
\hline & $\mathrm{T} 5$ & $6,6 \pm 0,19^{b}$ & $2,5 \pm 0,7^{b}$ & $1,13 \pm 0,15^{\mathrm{ab}}$ & $2,0 \pm 0,50^{\mathrm{a}}$ & $4,0 \pm 0,83^{a}$ & $12,9 \pm 3,2^{a}$ & $680 \pm 756^{b}$ \\
\hline & T0 & $6,0 \pm 0,33^{\mathrm{a}}$ & $3,3 \pm 0,27^{\mathrm{a}}$ & $1,21 \pm 0,17^{\mathrm{a}}$ & $1,2 \pm 0,1^{\mathrm{a}}$ & $2,2 \pm 0,37^{\mathrm{a}}$ & $7,2 \pm 3,8^{a}$ & $0,0 \pm 0,0^{\mathrm{b}}$ \\
\hline \multirow{5}{*}{ G4 } & $\mathrm{T} 1$ & $6,4 \pm 0,46^{\mathrm{a}}$ & $2,9 \pm 0,1^{\mathrm{a}}$ & $1,06 \pm 0,16^{\mathrm{a}}$ & $1,8 \pm 0,15^{\mathrm{a}}$ & $3,5 \pm 0,38^{a}$ & $11,3 \pm 4,0^{\mathrm{a}}$ & $686 \pm 551^{\mathrm{b}}$ \\
\hline & $\mathrm{T} 2$ & $5,9 \pm 0,61^{\mathrm{ab}}$ & $2,5 \pm 0,3^{b}$ & $1,01 \pm 0,24^{\mathrm{a}}$ & $1,7 \pm 0,29^{a}$ & $3,2 \pm 1,09^{\mathrm{a}}$ & $10,6 \pm 5,3^{\mathrm{a}}$ & - \\
\hline & T3 & $6,3 \pm 1,45^{\mathrm{a}}$ & $2,8 \pm 0,2^{\mathrm{a}}$ & $1,30 \pm 0,05^{\mathrm{a}}$ & $1,8 \pm 0,24^{\mathrm{a}}$ & $3,4 \pm 0,89^{a}$ & $11,1 \pm 9,2^{\mathrm{a}}$ & $817 \pm 444^{b}$ \\
\hline & $\mathrm{T} 4$ & $7,7 \pm 1,0^{\mathrm{a}}$ & $4,0 \pm 0,4^{\mathrm{a}}$ & $1,20 \pm 0,11^{\mathrm{a}}$ & $2,0 \pm 0,4^{\mathrm{a}}$ & $3,9 \pm 0,60^{\mathrm{a}}$ & $12,6 \pm 1,0^{\mathrm{a}}$ & \\
\hline & $\mathrm{T} 5$ & $7,6 \pm 0,4^{\mathrm{a}}$ & $3,2 \pm 0,7^{\mathrm{a}}$ & $1,26 \pm 0,11^{\mathrm{a}}$ & $1,7 \pm 0,5^{\mathrm{a}}$ & $3,3 \pm 0,94^{a}$ & $10,8 \pm 3,2^{\mathrm{a}}$ & $580 \pm 657^{b}$ \\
\hline
\end{tabular}

Os tempos (T) se referem aos dias de coleta: dia zero (T0), dia 20 (T1), dia 30 (T2), dia 45 (T3), dia 60 (T4) e dia 80 (T5). Letras não coincidentes denotam diferença estatística entre os valores e devem ser analisadas a partir da comparação com os mesmos momentos entre diferentes grupos. G - Grupos; PT - Proteína total; Alb - Albumina; Alfa - Alfaglobulina; Beta - betaglobulina; Gama - Gamaglobulina; TBARS - Espécies reativas ao ácido tiobarbitúrico; GSH-Px - Glutationa peroxidase

Nas gamaglobulinas, estão presentes os diferentes tipos de imunoglobulinas, sendo então a dosagem dessa proteína uma forma indireta de avaliar o estado imune de animais (LEAL et al., 2003; KANEKO et al., 2008).Os valores médios obtidos para a concentração de gamaglobulinas diferiram estatisticamente somente no T4 $(\mathrm{P}<0,01)$, quando o grupo 4 exibiu maiores valores dessa fração proteica em relação ao grupos infectados (1 e 2) (Tabela 1). Estudos demonstraram que o uso concomitante da vitamina E e do selênio resultou em melhora da resposta imune de pequenos ruminantes quando comparados à suplementação de apenas um dos elementos (FINCH \& TURNER, 1996; MILAD et al., 2001; LIESEGANG et al., 2008). Entretanto, MORGANTE et al. (1999) não observaram redução na incidência de mastite clínica em ovelhas suplementadas com selênio associado à vitamina E. A disparidade desses resultados sugere que o efeito desses elementos estão estritamente relacionados à dose de administração e situação orgânica animal. Como os animais do grupo 4 não foram desafiados experimentalmente pelo e $\boldsymbol{H}$. contortus, e receberam suplementação com selênio e vitamina E, houve um incremento dos valores das gamaglobulinas, demonstrando um estimulo do sistema imunológico dos cordeiros desse grupo em decorrência da administração desses elementos Os resultados obtidos para a proteína total, albumina e gamaglobulinas demonstram que possivelmente a dose de selênio e vitamina E administrada nos cordeiros severamente infectados 
pelo $\boldsymbol{H}$. contortus não foi suficiente para estimular a produção dessas proteínas.

Avaliando o perfil oxidativo dos animais, pôde-se observar que os valores de TBARS e GSHPx curiosamente se comportaram de forma semelhante, ou seja, quanto maior foi a produção de TBARS, maior foi os valores de GSH-Px (correlação positiva alta: $\mathrm{r}=1)$. No T4 $(\mathrm{P}<0,01)$, o grupo não infectado e suplementado com selênio e vitamina E (G4) demonstrou valores mais elevados de TBARS e GSHPx em relação aos grupos infectados pelo $\boldsymbol{H}$. contortus (1 e 2). A GSH-Px aumenta na circulação sanguínea em decorrência da maior disponibilidade de selênio sanguíneo, visto que é uma enzima dependente desse mineral (ROOKE et al., 2004; HALLIWELL \& GUTTERRIDGE, 2007). KATAMOTO et al. (1998) observaram uma tendência de maior atividade da GSHPx com a suplementação injetável de selênio e vitamina E, nas doses de: $0,1 \mathrm{mg} \mathrm{kg}^{-1}$ e $2,72 \mathrm{UI} \mathrm{kg} \mathrm{kg}^{-1}$, respectivamente, em cabras sob estresse térmico. No entanto, TAULER et al. (2002) avaliaram a suplementação via oral de vitamina $E$, na dose de $500 \mathrm{mg} / \mathrm{dia}$, associada a outros agentes antioxidantes (vitamina $\mathrm{C}$ e beta- caroteno) na dieta de atletas, verificando um aumento de $47 \%$ da atividade da GSHPx no grupo tratado.

Maiores valores de GSH-Px e TBARS foram observados no T4 $(\mathrm{P}<0,01)$ do grupo somente suplementado quando comparado aos dois grupos parasitados (Tabela 1). O selênio exerce varias funções biológicas no organismo quando incorporado em proteínas. Dado o grande número de seleno-proteínas, há mecanismos que regulam a prioridade de utilização de selênio de acordo com a necessidade orgânica (ROOKE et al., 2004). Essa hierarquia não se refere apenas à utilização de selênio dentro do mesmo tecido, mas também à retenção de selênio entre os tecidos (ROOKE et al., 2004). Animais infectados pelo $\boldsymbol{H}$. contortus apresentam deficiências minerais, sendo a suplementação uma forma de repor nutrientes necessários ao organismo animal.

Os cordeiros do grupo 4 não foram desafiados pela haemoncose e foram suplementados com selênio e vitamina E. Possivelmente, não foi necessária a utilização desses elementos pelos tecidos desses animais. Além disso, em situação em que não haja processo inflamatório ou necessidade de utilização da vitamina E, esta pode atuar como pró-oxidante, aumentando os valores de TBARS (COMHAIR \& ERZURUM, 2002; PAES et al., 2003). No entanto, a maior disponibilidade de selênio aumenta os valores de glutationa peroxidase na circulação. No presente estudo, pôde-se constatar um efeito compensatório entre os valores de GSH-PX e TBARS nos animais do grupo 4. Nos animais dos grupos parasitados, a dose de selênio e vitamina E provavelmente deve ter sido utilizada pelo organismo animal para suprir a carência de selênio e atuar no processo inflamatório gerado pela alta infecção parasitaria, não havendo aumento significativo nos valores de TBARS e GSH-Px.

\section{CONCLUSÃO}

A suplementação com selênio e vitamina E (IM), na dose de $0,1 \mathrm{mg} \mathrm{kg}^{-1}$ e $2000 \mathrm{UI}$ (duas aplicações com intervalo de 30 dias), respectivamente, não foi capaz de promover incremento proteico e imune quando cordeiros encontravam-se severamente infectados pelo Haemonchus contortus; já em cordeiros sadios, a suplementação com selênio e vitamina E promoveu aumento nos teores de proteínas séricas e melhorou a resposta imune animal.

\section{COMITÊ DE ÉTICA E BIOSSEGURANÇA}

Aprovado pelo comitê interno de ética em experimentação animal da ufsm sob protocolo número 51/ 2008

\section{APOIO FINANCEIRO}

Científico e Tecnológico

CNPq - Conselho Nacional de Desenvolvimento

\section{FONTES DE AQUISIÇÃO}

a - Laboratório Merck S.A. São Paulo, Brasil.

b - Laboratório Bravet Ltda. Rio de Janeiro, Brasil.

c - Levamisol: fosfato de levamisole, Laboratório Vetbrands Saúde Animal. São Paulo, Brasil.

d - Closalben: albendazole e closantel,Laboratório Vetbrands Saúde Animal. São Paulo, Brasil.

e - Cellogel: Labex S/A. Goiania, Goiás, Brasil.

\section{REFERÊNCIAS}

ADAMS, D.B. Systemic responses to challenges infection with Haemonchus contortus in immune merino sheep. Veterinary Research Communications, v.17, p.23 -35, 1993. Disponível em: <http://www.springerlink.com/content/ g82686356w110u71/> . Acesso em 26 nov.09. doi: 10.1007/ BF01839177.

ALONSO, M.L. et al. Glutatión peroxidasa (GSH-PX) em las patologias asociadas a deficiências de selênio em ruminantes. Archivos de Medicina Veterinária, v.29, n.2, p.171-180, 1997. Disponível em:< http://www.scielo.cl/scielo.php?pid=S0301732X2002000100005\&script $=$ sci_arttext $>$. Acesso em 26 nov.09. doi: 10.4067/S0301-732X1997000200001.

ARTHUR, J.R. et al. Selenium in the immune system. Journal of Nutrition, v.133, p.1457-1459, 2003. 
BAKER, R.L. Characterization and utilization of sheep and goat breeds that are resistant to helminths. In: LE JAMBRE, L.F.; KNOX, M.R. Sustainable parasite control in small ruminants. Bogor: ACIAR, 1996. p.172-177. (Proceedings, n.74).

BLACKBURN, H.D. et al. Interactions of parasitism and nutrition in goats affects on haematological parameters, correlations and other statistical associations. Veterinary Parasitology, v.44, n.3-4, p.183-197, 1992. Disponível em: <http://www3.interscience.wiley.com/journal/119398905/ abstract?CRETRY=1\&SRETRY=0>. Acesso em: 04 de dez. 2009. doi: 10.1016/0304-4017(92)90116-Q .

COMHAIR, S.A.A.; ERZURUM, S.C. Antioxidant responses to oxidant-mediated lung diseases. American Journal Physiology Lung, v.283, p.246-255, 2002. Disponível em: <http://ajplung.physiology.org/cgi/content/full/283/2/L246>. Acesso em: 26 nov. 09. doi:10.1152/ajplung.00491.2001.

CHIHUAILAF, R.H. et al. Pathogenesis of oxidative stress: Consequences and evaluation in animal health. Veterinary México, v.33, n.3, p.265-283, 2002.

DRÖGE, W. Free radicals in the physiological control of cell function. Physiology Review, v.82, p.47-95, 2002. Disponível em: <http://physrev.physiology.org/cgi/content/full/ 82/1/47>. Acesso em: 26 de nov.2009. doi: 10.1152/ physrev.00018.2001.

ELLMAN, G.L. Tissue sulphydril groups. Archives Biochemistry and Biophysics, v.82, p.70-77, 1959.

FINCH, J.M.; TURNER, R.J. Effects of selenium and vitamin $\mathrm{E}$ on the immune responses of domestic animals. Research in Veterinary Science, v.60, p.97-106, 1996. Disponível em: $<$ h t t p : / / w w w. s c i e n c ed i rect. c o m/ science?_ob=ArticleURL\&_udi=B6WWR-4CWRY1V$58 \&$ \&user $=687358 \&$ \&_doc $=1 \&$ \&_fmt $=$ \&_orig $=$ search $\&>$. Acesso em: 04 de dez. 2009. doi:10.1016/S00345288(96)90001-6

GIERUS, M. Fontes orgânicas e inorgânicas de selênio na nutrição de vacas leiteiras: digestão, absorção, metabolismo e exigências. Ciência Rural, v.37, n.4, p.1212-1220, 2007. Disponível em: <http://www.scielo.br/pdf/cr/v37n4/ a52v37n4.pdf >. Acesso em: 04 de dez. 2009. doi: 10.1590/ S0103-84782007000400052.

HALLIWELL, B.; GUTTERIDGE, J.M.C. Free radicals in biology and medicine. 6.ed. New York: Oxford University, 2007. 851p.

KANEKO, J.J. et al. Clinical biochemistry of domestic animals. 6.ed. New York: Academic, 2008. 896p.

KATAMOTO, H. et al. Nitroblue tetrazolium reduction of neutrophils in heat stressed goats is not influenced by selenium and vitamin E injection. Journal Veterinary Medicine Science, v.60, n.11, p.1243-1249, 1998.

KAZURA, J.W; MESNICK, S.R. Scavenger enzymes and resistance to oxygen mediated damage in Trichinella spiralis. Molecular Biochemical Parasitology, v.10, p.1-10, 1984.

LEAL, M.L.R. et al. Proteinograma sérico de bezerras sadias da raça Holandesa no primeiro mês pós-nascimento. Brazilian
Journal of Veterinary Research and Animal Science, v.40, n.2, p.138-145, 2003. Disponível em: <http:// www.scielo.br/pdf/bjvras/v40n2/v40n2a08.pdf>. Acesso em: 04 de dez.2009. doi: 10.1590/S1413-95962003000200008.

LIESEGANG, A. et al. Effect of vitamin E supplementation of sheep and goats fed diets supplemented with polyunsaturated fatty acids and low in Se. Journal Animal Physiology and Animal Nutrition, v.92, p.292-302, 2008. Disponível em: $<$ http://www3.interscience.wiley.com/journal/119408467/ abstract>. Acesso em: 04 de dez. 2009. doi: 10.1111/j.14390396.2007.00770.x.

LOPES, S.T.A. et al. Atividade funcional neutrofílica em cabras com mastite induzida experimentalmente por Staphylococcus aures e suplementadas com vitamina E (acetato DL-alfa-tocoferol. Arquivo Brasileiro de Medicina Veterinária e Zootecnia da UFMG,v.55, nz 5, p.515-521, 2003. Disponível em: <http:// www.scielo.br/scielo.php? script=sci_arttext\&pid=S010209352003000500001>. Acesso em: 04 de dez. 2009. doi: 10.1590/ S0102-09352003000500001.

MEYDANI, M. Vitamin E. Lancet, v.345, p.170-175, 1995.

MILAD, K. et al. Effect of vitamin E and selenium on blood glutathione peroxidase activity and some immunological parameters in sheep. Veterinary Medicine, v.46, n.1, p.1-5, 2001.

MORGANTE, M. et al. Effect of administration of vitamin E and selenium during the dry period on mammary health and milk cell counts in dairy ewes. Journal Dairy Science, v.82, p.623-631, 1999.

NORDBERGER, J.;ARNER, E.S.J. Reactive oxygen species, antioxidants and the mammalian thioredoxin system. Free Radical Biology \& Medicine, v.31, n.11, p.1287-1312, 2001. Disponível em: <http:// www.sciencedirect.com/science?_ob=ArticleURL\&_udi=B6T3844HSN76-1\&_user=687358\&_rdoc $=18 \_f m t=8 \_o r i g=$ search\&_sort $=$ d\&_docanchor $=\&$ view $=$ c\&_ searchStrId $=1162214741$ \&_rerun Origin=google \&_acct $=$ C $000037899 \&$ \&_version $=1 \&$ _urlVersion $=0 \&$ \&userid $=687358 \&$ md $5=756 \mathrm{~d} 2422 \mathrm{~b} 2$ 1d77f4b81b74ac54162f67>. Acesso em: 04 de dez. 2009. doi:10.1016/ S0891-5849(01)00724-9.

OHKAWA, H. et al. Assay for lipid peroxides in animal tissues by thiobarbituric acid reaction. Analytical Biochemistry, v.95, p.351-358, 1979.

PAES, P.R.O. et al. Efeitos da administração de vitamina E na infecção mamária e na contagem de células somáticas de cabras primíparas desafiadas experimentalmente com Staphylococcus aureus. Arquivo Brasileiro de Medicina Veterinária e Zootecnia, v.55, n.1, p.15-20, 2003.

PAULA E SILVA, R.O. et al. Eletroforese de proteínas séricas: interpretação e correlação clínica. Revista Médica de Minas Gerais. v.18, n.2, p.116-122, 2008.

RAMIREZ-BRIBIESCA, J.E. et al. Effect of selenium-vitamin E injection in selenium-deficient dairy goats and kids on Mexican plateau. Arquivo brasileiro de Medicina Veterinária, v.57, n.1, p.77-84, 2005. Disponível em: <http://www.scielo.br/ scielo.php?pid=S0102-9352005000100011\&script=sci_abstract $>$. Acesso em: 04 de dez. 2009. doi: 10.1590/S010209352005000100011. 
RIEGEL, R.E. Radicais livres. In: São Leopoldo: Unisinos, 2000. p.507-536.

ROBERTS, F.H.S.; O’SULLIVAN, J.P. Methods for egg counts and larval cultures for strongyles infesting the gastrointestinal tract of cattle. Australian Agriculture Research, v.1, p.99102,1950

ROOKE, J,A. et al. Effects of vitamin $\mathrm{E}$ and selenium on the performance and immune status of ewes and lambs. Journal Agricultural Science, v.142, p.253-262, 2004. Disponível em: $<$ ht t p :// journals. cambridge.org/action/ dis p la y Fulltext ? t y p e = $1 \&$ fi d $=266020 \&$ j $\mathrm{d}=$ AGS\&volumeId=142\&issueId=03\&aid=266019>. Acesso em: 04 de dez. 2009. doi: 10.1017/S0021859604004368.

ROWE, A. et al. Genomic analyses of Haemonchus contortus infection in sheep: abomasal fistulation and two Haemonchus strains do not substantially confound host gene expression in microarrays. Veterinary Parasitology, v.154, p.71-81, 2008. Disponível em: <http://www.sciencedirect.com/ science?_ob=ArticleURL\&_udi=B6TD7-4RX077C$2 \&$ _ u s e r $=687358$ \&_ r d o c $=1 \&$ _ f m t $=\&$ _orig =search\&_sort $=$ d $\&$ _docanchor $=\&$ view $=$ c $\&$ \&ea rchStrId $=1162234561 \&$ \&rerunOrigin $=$ google\&_acct $=\bar{C} 000$ $037899 \& \quad$ version $=1$ \& url Versio $n=0$ \&_u s e r i d $=687358 \&$ m d $5=$ d 86 faa04efaf2063ec9969745fea417a>. Acesso em: 04 de dez. 2009. doi:10.1016/j.vetpar.2008.02.014.

SAMPAIO, I.B.M. Estatística aplicada à experimentação animal. Belo Horizonte: Fundação de Ensino em Medicina Veterinária E Zootecnia, 1998. 221p.

SCHANAIDER, A. Radicais livres: vilões ainda em estudo. Ciência Hoje, v.27, n.158, p.60-62, 2000.

TAULER, P. et al. Diet supplementation with vitamin E, vitamin $C$ and $ß$-carotene cocktail enhances basal neutrophil antioxidant enzymes in athletes. Archives European Journal Physiology, v.443, n.5-6, p.791-797, 2002.

VALKO, M. et al. Free radicals and antioxidants in normal physiological functions and human disease. International Journal of Biochemistry \& Cell Biology, v.39, p 44-84, 2007. Disponível em: <http://www.sciencedirect.com/ science?_ob=ArticleURL\&_udi=B6TCH-4KJTYSJ18 user $=687358$ \&_rdoc $=1$ \&_fmt=\&_orig=search\&_sort=d\&_docanchor $=$ \&vie $\mathrm{w}=\mathrm{C} \&$ \&searchStrId $=1162236501$ \&_rerunOrigin $=$ google\&_acct $=\mathrm{C} 0000$ $37899 \&$ \&_version $=1 \&$ \&_url Version $=0 \&$ \&_useri $d=6$ $87358 \& \mathrm{md} 5=28 \mathrm{ecb} 2 \mathrm{~b} 5 \mathrm{~d} 1240 \mathrm{f} 21 \mathrm{cc} 04 \mathrm{fa} 82 \mathrm{a} 32 \mathrm{fa} 445>$. Acesso em: 04 de dez. 2009. doi:10.1016/j.vetpar.2008.02.014. 